\title{
Difficulties of Scientific research facing educational supervisors in Directorates of education of Irbid Governorate from their point of view
}

\author{
Dr. Kholoud S Yaghmour \\ Associate Professor, Dep. of Educational Science, Al-Balqa Applied University, Irbid College
}

\section{Dr. Luai Taleb Obaidat}

Assistant Professor, Jadara University/ College of Educational Sciences/ Kindergarten Department

\section{ABSTRACT}

The study aimed to identify difficulties of scientific research facing educational supervisors in Directorates of education of Irbid Governorate from their point of view. The study sample consisted of (226) male and female supervisors. To achieve the objectives of the study, the inferential and descriptive analysis method was adopted. A questionnaire consisted of (27) items, where its validity and reliability were verified. To achieve the objectives of the study, the Statistical Package for the Social Sciences (SPPS) was used such as frequencies and percentages, arithmetic means, standard deviations, Cronbach's Alpha, MANOVA and ANOVA tests. Through referring to the results, we find the arithmetic mean value of difficulties of scientific research facing educational supervisors in Directorates of education of Irbid Governorate was 4.49, which is considered a high value referring to the scale used in the study. The results also revealed statistical significance differences among means of the study population individuals about difficulties facing educational supervisors in Directorates of education of Irbid Governorate, and these differences are due to female supervisors where their mean was bigger than the males' which reached 4.55. The results showed that were statistical significance differences among supervisors of high diploma. The results also showed that there were statistical significance differences among supervisors whose experience in supervision is less than 5 years.

Article Received: 18 October 2020, Revised: 3 November 2020, Accepted: 24 December 2020

\section{Introduction}

The supervisory process receives a clear interest as it is one pillar of the educational system in Jordan, where the educational supervision is responsible for field follow up to ensure achievement of goals and objectives of education based on the approved policies. The educational supervisor is considered to be the link between the educational field and administration where he conveys his thoughts and views about workflow properly in addition to the shortage that may occur after he identifies the nature of educational practices by observation, researches and studies (Abu Rahma, 2012).

The educational supervision in Jordan has experienced three stages which are: supervision stage (1921-1962) which concentrated on the teacher's performance and school subject with its narrow concept; the visits were surprising and the teacher has to accept instructions and implement them, and the assumption of the supervisor's excellence on the teacher has prevailed regarding methods of teaching and its means, and the follow up was little that ends with the end of the preparation of the visit report (Ministry of Education, 2011). The educational guidance stage (1962-1975) which concentrated on cooperation and exchange views with the teachers, move away from making judgments and instructions and expand the extent of the supervisor's practices to cover the school textbook, classroom environment, teaching aids and educational facilities. Then, transfer to the educational supervision stage (19752008) where the term of educational guidance was replaced with educational supervision since it is more important, comprehensive, boarder and general , and upgrading the practices to upper level because it is an organized, cooperative and democratic leadership process aims to study, improve and evaluate the effective factors in that situation. This means that the educational supervision is a process based on studying and investigation instead of inspection, and it includes 
all of the elements of the educational process such as the curriculum, aids, teacher, learner and environment instead of concentration on the teacher alone (Eideh, 2007; Yaghmour et al., 2016).

The educational supervisor is one of the most important means that can effectively contribute in the educational process through what he performs from management and activities that organize students' interactions together, the students and the teacher or the students, the teacher and supervisor himself (Musaed, 2000). The role of the educational supervisor emerged in the educational process through activating the teachers' performance so that the educational objective is achieved effectively and efficiently. The educational supervision forms a continuous evaluation process aims to support the teacher through discussing the positive and negative issues in his work, and provide continuous guidance in order to raise the level of his experiences and skills, and work to increase his effectiveness (Shdaifat, 2014).

The educational supervision has received the educators attention in the different educational systems and among all of the educational levels, its methods also varied by the time, its styles developed clearly during the past decades, where supervision was at the beginning traditional based on inspection, hunt of mistakes, it developed into the stage of educational supervision and guidance, which means directing the teacher's work and his teaching practices to achieve the objectives of the educational process. As a result of this development in the supervisory methods, many sorts of educational supervision styles appeared such as: integrated, diplomatic, corrective, clinical, democratic, leadership and developmental supervision. Therefore, the diversity of educational supervision methods according to the diversity of teachers' characters, experiences and trends which are considered of the important strategies in improving educational teachers practices, considering individual differences among them and contributing in achieving professional development among them (Shdaifat and Al-Qadiri, 2005).

The educational role that the supervisor is assumed to perform is a complex one; because the educational supervisor is responsible for developing the teachers' abilities and follow up the students' growth through them. He is also required to perform other roles related to the curriculum and its evaluation and the educational aids and their evaluation, too; therefore, the supervisor's tasks are many that required him to be qualified and trained well enough to perform them (Abu Rahma, 2012).

\section{The study problem and questions}

Some Arab countries or some administrations in them don't realize the value of scientific research, and thus they don't work hard to reinforce it and facilitate its affairs; they think that it is intellectual or scientific luxury and no need to waste money and effort on scientific researches. This problematic is reflected in many other points in the scientific research procedures (Hordo Center, 2015). On the basis of the two researchers' study of the subject of educational supervision, its development and difficulties of scientific research, in addition to the importance and high status of the educational supervision in improving the educational process outputs, where the educational supervisor is considered to be the building block in the educational work, so the study problem emerged through the staying away of many educational supervisors from the scientific research although of its importance in the educational process in innovating methods and strategies which their role is to develop the educational process and deliver information to the student in a simple way without any complexity and referable to the student. Although there is a system of ranks in the Ministry of Education and promotion to a rank of an expert teacher which depends on writing educational researches, there is a shortcoming in writing educational researches which improve their practical and professional growth and they don't give them the proper importance. It is noticed that few of educational supervisors who prepared scientific researches in 
order to obtain promotion, and this may refer to that they don't know the basis of scientific researches and how to do them with a clear scientific methodology. Therefore, the problem of the study was represented in the difficulties of scientific research in the directorates of education in Irbid Governorate from their point of view, and based on the above; this study came to answer the following questions:

1. What are the difficulties of scientific research among the educational supervisors in the directorates of education in Irbid Governorate from their point of view?

2. Are there any statistical significant differences at the level $(\alpha=0.05)$ among arithmetic means to the estimates of the study population individuals of the difficulties of the scientific research facing the educational supervisors in the directorates of education in Irbid Governorate from their point of view (sex, scientific qualification, experience on supervision).

\section{Importance of the study}

The need for studies, researches and learning at present became more than any past time. The science and world are in a competition to reach the biggest amount of knowledge derived from science that ensures luxury for human, and guarantees excellence for him. If the developed countries gave great attention to scientific research, this refers to that they realized the greatness of nations lies in behavior, intellectual and scientific abilities of their sons. The scientific research is a fertile area and major base of the countries' economies and their developments, and thus achieving luxury for their people and preserves their international status.

The methodology of the scientific research and the methods to do are from things for granted in the academic institutions and researches centers, in addition to their spread of their usage in treating problems facing the society in general, where the scientific isn't restricted to fields of natural sciences alone (Hordo Center, 2015). It is expected that this study will enable the educational decision makers in the Ministry of Education to adopt the best methods to develop scientific researches and encounter the obstacles facing hem through introducing indicators that explain the supervisory fact of the educational supervisors. The current study reveals the needs of scientific research which supervisors need of their various specialists. The study also derives its importance through mentioning the difficulties and obstacles in general which related to the research climate that is improper particularly for teachers to enable them to perform their educational and scientific tasks in the Ministry of Education, and reveal the scientific task, since it is a core, functional task if not the most important academic and scientific function. The study of research production of the educational supervisors will introduce essential information for those in charge of Ministry of Education and decision makers in order to improve the fact of scientific research and work to develop it in order to upgrade the level of educational supervision performance to the best possible extent.

\section{Objectives of the study}

- Identify the obstacles of the scientific research facing educational supervisors in the directorates of education in Irbid Governorate from their point of view.

- Identify the differences among arithmetic means of the study population estimates of the difficulties of scientific research facing the educational supervisors in the directorates of education in Irbid Governorate from their point of view due to (sex, scientific qualification and experience on supervision).

\section{Limits of the study}

The current study restricted to the following limits: - Subjective limit: The study dealt with the difficulties of the scientific research among the educational supervisors in the directorates of education in Irbid Governorate from their point of view.

- Spatial limit: This study was applied on the directorates of education in Irbid Governorate because of the facilities they introduced to apply the study. 
- Human limit: The study was applied to all of male and female supervisors in the directorates of education in Irbid Governorate.

- Time limit: This study was applied in the first semester of the academic year 2019/2020.

\section{Procedural definitions}

- Obstacles: Trammels related to the technical and administrative aspect, and the researchers defined them as they form a challenge to the educational supervisor in preparing the scientific research which reduces the educational supervisor's achieving of his goals.

- Educational supervisors: They are who assigned by the Ministry of Education based on specific principles to practice the supervisory process in schools in order to direct, guide, improve and follow up employees in the two academic and educational aspects.

Scientific research: it is measured by the degree that the researchers get through the responses of the research sample individuals on the items of the tool prepared for this purpose.

- Their point of view (supervisors): That response which shows the supervisors degree in the directorates of education in Irbid Governorate on the content of the items of the questionnaire of the study.

\section{Literature review}

\section{Scientific research}

Science represents a central social bet, as science is a field which the strategies of research, development, innovation of purely scientific dimensions cross inside it, in addition to critical effects on competition abilities of the international economics fall on the shoulders of universities and institutions of the scientific research which lead the integrated cognitive and scientific renaissance in all different aspects of life. The scientific research gives university its actual meaning and distinguish it from the rest of institutions, so the western universities gave a special care to the scientific research and allocated budgets for it, and attracted the scientific competences where its areas covered all aspects of life to lead their people to development and growth, and in turn in our Arab world we find that the scientific research wasn't given that importance, and this was reflected on the factors of this field of researchers and universities alike which negatively affected to perform its role in research and innovation functions, advancement of Arab societies and push their march towards progress (Al- Gharam, 2015).

Scientific research is the basis of the progress of society, and in order that this aspect gives its results, it must be featured by originality as the first step to be it's exploited by rewarding the one who is the first of achievement, where this will encourage the scientific competencies acclaimed for their distinguish to follow the same approach because what supports these achievements is their originality to whoever invented and wrote them.. If this principle is the origin, there are those who get out from it through not respecting the principle of scientific honesty. If these practices are an exception, they can be dealt with easily, but if they stared to spread to become a phenomenon, then they should be stopped and the alarms sounded in order we alert to them and their disastrous effects on scientific research, the Algerian university and future of all frames derived from them (Mrain and Tawahria, 2018).

The importance of this study will be as what it provides humanity with new benefits; that they help them to worship God, contribute in answering their question, achieve progress in the lives, solve a problem or increases one aspect of knowledge. The importance of scientific research increases if it treats a serious issue in people's life that they need. Thus, the researchers studies the subject after defining its problem (subject) to reach logic results that provide human with benefits as a whole or part of it.

The importance of the scientific research emerges in introducing the conclusion of a continuous effort by those of experience and competence which helps the advancement of human societies in all of its aspects, introduces correct information based on scientific principles that help them to spread the correct thought among people and contributes in developing and progressing the society (AlTartoury, 2010). 
Farid (2018) defined the scientific research as an accurate study of a definite problem or phenomenon that can be discussed and researched, where its goal is to find solutions to the phenomenon under study through deep tests of the suggested hypothesis and based on using a comprehensive approach to investigate all of the evidence that help us to interpret the phenomenon which finally leads to generalization. (United Nations Humanitarian Program, 2003) defines the scientific research as inevitability of phenomena and organized group methodology to possess specific type of knowledge or other. As for Marazqa (2013) he defined it as the outcome of an organized effort aims to answer the related questions to a subject, and it is an attempt to discover knowledge, search for and improve, check, investigate and criticize it accurately, then display it completely with care and cleverness.

Obstacles of scientific research in the Arab world

The developed countries have achieved excited results due to their interest in scientific research through setting strategies plans and clear policies to support activities of scientific research in providing money, tools, automatic devices, building colleges and laboratories, Recruiting distinguished intellectual human capital prepared and formed according to a strong educational system based on free creative thinking; the output was strong in terms of economic growth and knowledge and technical control.

The developed countries' policy mainly depends on Spending generously on their institutions, offering modern infrastructure of electronic devices, forming efficiencies and scientific abilities like researchers and research assistants, encouraging scientific contact and group work through research teams that have creative, intellectual and academic freedom (Shdaifat, 2014).

Studies ensured that to build a strong scientific base, two main supporters should be available which are human capital featured with scientific and intellectual abilities, and material capital which provides with material resources in order to do intellectual activity (Shdaifat, 2014).

Obstacles related to human resource

The importance of human capital was ensured before in developing scientific research, and it was also pointed to the weak proportion of researchers which Arab countries include which refer to lack of caring about these cadres from one hand, and escape of Arab elite abroad from the other hand. We can conclude the obstacles related to human resources as follows:

- Shortage of researches and competences, rarely formation integrated research teams and ignoring their continuous formation.

- Ignorance of formation of researchers in foreign languages and the area of using modern technologies.

- Low interest with Arab researcher and no offering of scientific atmosphere away from bureaucratic and ignorance.

- No good planning of scientific scholarships and dispatching abroad although of high costs that the country bears in this aspect.

- The lack of a scientific motivated climate to scientific research and invest creative and innovative abilities of individuals.

-There is no enough academic movement as that featured by scientific research in the West.

\section{Materialistic and financial obstacles}

The materialistic element is considered one of the helping factors to upgrade the scientific research in Arab world, so we find it one of the most important obstacles of intellectual and scientific renaissance where its features are as follows (Masoudan, 2018): - The issue of weak funding: Spending on scientific research isn't considered to be a waste but it is an investment if it is exploited well, and there is an international agreement on the proportion of spending on scientific research and development of $1 \%$ from the total local income, where this rate of spending may achieve an important effect in the different sectors of the society, and what is below this level is considered to be useless spending.

- Weak funding management and, poor management of the financial budget allocated to scientific research, and weak absorption ability of 
available funds because scientific research institutions complained from imbalances in the field of funding management, legal gaps, and pragmatic basis in the formation of the network of relationships and links among research and social institutions and also among individual researchers themselves.

- Absence of financial support from economic sectors and society institutions generally, where we observe that spending on scientific research is done from the country budget only and of a proportion $100 \%$, which leads to shortcoming of link between social research topics and local reality, which means the absence of a feature research, development - material problems and equipment. In general, it can be said that social research in the university suffers from a lack of the required material and preparation fundament, and in its position obstructs its progress, although social research does not require much equipment with comparative compared to applied sciences.

\section{Research skills}

The researchers can't acquire research skills quickly, where the issue needs much time and effort from starting the MA leading to the Ph.D. and even reach further than that. There two ways to acquire these skills through which are the way of consciousness and the subconscious, and in both cases he researcher goes through the training stage firstly, followed by the practical process. There are two methods to acquire those skills (Maden, 2012):

- The first method: The researchers acquire skills through awareness and realize what another person does of techniques, or learns methods of using software which he needs in the research.

- The second method: Subconscious, where the researcher is in a research environment and he is influences with researchers around him, a she sometimes learns from them how to read, analyze and implement studies, and sometimes learns from them how to explain their thoughts to others easily and skillfully. He also learns how to overcome the problems facing his study through the study supervisor.

Related studies
Through revision of the literature review, some studies were revised which share with one of the objectives of this study which is the difficulties of the scientific research such as Al-Zoubi study (2018) which aimed to investigate the difficulties that the high studies students in Jordanian universities suffer from writing the MA and Ph.D. thesis from the point view of the supervisors and members of discussion committees. A questionnaire was done which consisted of nine domains. The results of the study showed that high studies students face difficulties in the nine domains with various degrees ranged between big difficulties to medium ones, where they were ordered as follows: introduction, display and interpret the results, title, the study problem and questions, suggestions, recommendations, methodology of the study, documentation of references, study limits and limitations and the student's relation with the supervisor. The study also found that the degree of difficulty facing students of higher studies in human faculties in five domains (Title, introduction, study problem and questions, display results and interpretation, references) were higher than the difficulties facing students of higher studies in scientific faculties.

Al-Dhaw study (2018) aimed to identify the quality level of scientific research of students of higher studies in Sudanese University of Bakht Al-Rida from the faculty members' point of view. The size of study sample was (60) faculty members which represents all of faculty members who were supervisors of students of higher studies in those faculties which is an intentional sample, where the descriptive method was adopted. The study concluded that the quality level of scientific research of students of higher studies in University of Bakht Al-Rida was with a high degree. The study also showed that there no differences in the quality level of scientific research of students of higher studies in University of Bakht Al-Rida due to the two variables of sex (male, female), and the academic rank (associate Professor, assistant Professor), and there were differences in the level of scientific research quality of students of higher 
studies in University of Bakht Al-Rida due to the faculty variable and for the faculty of education.

Abboud (2018) conducted a study aimed to identify the degree to which Islamic education teachers possess scientific research skills in Jordan from their point of view. The researchers developed the study tool, which is a questionnaire consisted of (43) items, where its validity and reliability were approved, then it was distributed to a random sample consisted of (250) male and female Islamic education teachers in the Directorate of Education of First Amman. The results of the study showed that the whole degree of Islamic education teachers' possession of scientific research skills in Jordan, from their viewpoint was with a medium degree. The results of the study also showed that there were statistically significant differences in the effect of gender in all fields for females, and for the scientific qualification in all fields which were for holders of a Ph.D. There were no statistically significant differences due to the effect of years of experience. The study also revealed that there were no statistically significant differences due to the effect of the number of training sessions on the tool as a whole.

Al-Hamshari (2017) conducted a study aimed to identify the difficulties of scientific research among students of higher studies (MA) in Zarqa University from their point of view. The study community consisted of (220) male and female students registered for the first semester of the year $2016 / 2017$. The tool of the study was distributed to all of them, where (119) of them responded. A questionnaire was developed to collect data, where its validity and reliability were approved. The results showed that the whole degree of the study individuals' estimates of the difficulties facing them was medium, and all of the domains of these twelve difficulties also got medium degrees of difficulties. The most important difficulties were respectively: formulation of the study title, study problem and questions, introduction, study method and procedures. The results of the study also revealed that there no significant differences among arithmetic means of the study individuals' responses on intended difficulties from their point of view based on the study variables: study progress, academic year, sort of faculty and sex. Rimawi and Kurdi (2015) study aimed to identify the obstacles of scientific research from the point of view of faculty members of human faculties of Quds University. The questionnaire of obstacles of scientific research was used which consisted of (45) items to collect the data of the study through a random stratified sample reached (63) faculty members of human faculties of Quds University. The results of the study showed that there were no statistical significant differences in means of obstacles of the scientific researches related the different of scientific rank, years of experience and numbers of researches, whereas there were statistical significant differences related to faculty members for the work of the variable of the nature of work of academic members.

The study of Al-Rifai and Gibran (2015) aimed to investigate the problems of scientific research among faculty members in Jordanian public universities, and their relationship to some variables. The researchers adopted the descriptive and analytical approach, and the researchers also built a questionnaire distributed into five areas which were: personal, administrative, scientific, political and financial. The study adopted the intentional sample, which is composed of (142) faculty members in four Jordanian public universities: Yarmouk, Science and Technology, Al-Balqa Applied and International Islamic Sciences The study concluded that the problems of scientific research in the Jordanian universities introduced in the scale were approved by the sample with a high degree on the overall domain of the scale, and that the three sub-domains: administrative, financial and political have a basic rank with a high degree, where the administrative problems rank was first among the problems of official research, the financial and political problems are in the second and third ranks respectively, whereas the domains of personal and scientific problems didn't show a basic rank compared to the rest of the domains. In addition, there were no statistically significant differences in the degree of agreement of scientific research 
problems for any of the variables of study on the whole domain of the scale, while there was a basic difference emerged for the age group variable on the domain of political problems for the age group between 33-54 years.

(Taylor, 2007) conducted a study aimed to identify the visions of student of high studies about scientific research. The students were divided into three groups related to the process of learning research: the first was experimental which consisted of students who receive information about scientific research and wait to learn research by expert teachers, the second consisted of students who considered themselves collecting of information and option and the third was called "critic participators" who formed their knowledge depending on amendment and change through practicing questions in order to address questions, check assumptions and suggest alternatives.

(Reis, 2007) study aimed to identify skills that students of higher studies need in scientific research. The results showed that these students should learn how to do research which helps them to transfer from a stage where they are critics of scientific research to be productive and creative in the related area.

\section{Comment on the related studies}

Through writing theoretical literature and looking for related studies dealt with scientific research, it was found that there was no study that dealt with the difficulties of scientific research among the educational supervisors who work in the Ministry of Education. Through looking at the dealt studies, it was observed that they were investigated in scientific research in universities, such as the study of (Al-Zoubi, 2018; Al-Dhaw, 2018; Al-Hamshari, 2017; Rimawi and Kurdi, 2015; Al-Rifai and Gibran, 2015). There was one study dealt with scientific research in the Ministry of Education and applied to teachers of Islamic education which was the study of (Abboud, 2018). It was also noticed that all of the studies used the questionnaire as a tool to reveal their variables such as the study of (Al-Rifai and Gibran, 2015) and (Al-Hamshari, 2017). It was also noticed that researches were done in many countries such as in Jordan the study of (Al-Zoubi, 2018; Abboud, 2018; Al-Hamshari, 2017), in Sudan (Al-Dhaw, 2018), in Palestine (Rimawi and Kurdi, 2015). It has been benefited from the previous studies by revising the literature of them and identified the results that the studies have concluded and transfer them to supervisors in the field in order to be adopted and practiced.

The study methodology

A comprehensive study was conducted for the supervisors of Irbid governorate to measure the difficulties of the scientific research facing them from their point of view, where the descriptive and deductive analysis was used to measure the difficulties of scientific research facing the educational supervisors in the Directorates of education in Irbid Governorate

Analysis and discussion of the study results The society of the study to investigate the difficulties of scientific research facing the educational supervisors in the Directorates of education in Irbid Governorate from their point of view consisted of all of male and female educational supervisors in the directorates which reached (251), where a survey sample was taken to measure the reliability of the tool of the study, and the study population was divided into (169) male supervisor and (57) female supervisor.

The study sample

The society of the study to investigate the difficulties of scientific research facing the educational supervisors in the Directorates of education in Irbid Governorate from their point of view consisted of (226) male and female supervisors distributed according to sex, scientific qualification, experience in educational supervision as shown in table No.1

Table 1: Number and percentage of male and female of supervisors of study population of difficulties of scientific research facing educational supervisors in the Directorates of education in Irbid Governorate from their point of view according to sex, scientific qualification, experience in educational supervision 


\begin{tabular}{|c|c|c|}
\hline Variable & Number & Percentage \\
\hline \multicolumn{3}{|c|}{ Sex } \\
\hline Male & 169 & 74.8 \\
\hline Female & 57 & 25.2 \\
\hline \multicolumn{3}{|c|}{ Scientific qualification } \\
\hline $\mathrm{PhD}$ & 69 & 30.5 \\
\hline MA & 16.5 & 143 \\
\hline High Diploma & 18 & 8 \\
\hline \multicolumn{3}{|c|}{ Experiences in educational supervision } \\
\hline Less than 5 years & 32.3 & 73 \\
\hline From 5-10 years & 39.4 & 89 \\
\hline $\begin{array}{c}\text { From } 10 \text { years and } \\
\text { more }\end{array}$ & 28.3 & 64 \\
\hline
\end{tabular}

Table (1) shows that the number of male supervisors was 169 with a percentage of $74.8 \%$, while the number of females was 57 with a percentage of $25.2 \%$. The number of supervisors who have qualifications of Ph.D. was 69 with a percentage of $30.5 \%$, the MA is 143 with a percentage of $61.5 \%$ and the high diploma was 18 with a percentage of $8 \%$, whereas the number of supervisors whose experience in supervision less than 5 years was 73 with a percentage of $32.3 \%$, supervisors whose experience between 5-10 years was 89 with a percentage of 39.4 and whose experience is more than 10 years is 64 with a percentage of $28.3 \%$.

\section{The study tool}

To achieve the objectives of the study, the two researchers developed the tool after revision of the literature and related studies with difficulties of scientific research. The questionnaire of difficulties of scientific research facing the educational supervisors in the Directorates of education in Irbid Governorate from their point of view included (27) questions where all of them were to measure these difficulties.

\section{Validity of the tool}

To ensure the validity of the tool, it was introduced in its primary image to (8) arbitrators of faculty members in some Jordanian universities, educational supervisors and school principals, where they all were asked to give notes about the items of the questionnaire according to language, degree of the item representation of its domain, adding new items and deleting items. In the light of this, some amendments were conducted on the items of the questionnaire, where the total of items that the questionnaire ended with was (27) items.

To identify the extent of harmony among items of the test and the test as a whole, it was applied to a survey sample consisted of (25) male and female supervisors outside of the study sample, where correlation coefficients were counted between each item and the test as a whole using Pearson Correlation Coefficient, and the correlation coefficient was positive and no less than 0.30 and statistically significant in order that the test is featured with a degree of validity.

To ensure of indications of the constructive validity of the test, it was applied to a survey sample consisted of (25) male and female supervisors outside of the study sample and the society itself, where correlation coefficients were counted between each item and the test as a whole, and Table (2) shows that. 
Table (2) constructive validity correlations (Correlation between each item and the test as a whole)

\begin{tabular}{|c|c|c|c|c|c|}
\hline Number & $\begin{array}{c}\text { Item } \\
\text { correlation } \\
\text { with test as } \\
\text { a whole }\end{array}$ & Number & $\begin{array}{c}\text { Item } \\
\text { correlation } \\
\text { with test as } \\
\text { a whole }\end{array}$ & Number & $\begin{array}{c}\text { Item } \\
\text { correlation } \\
\text { with test as a } \\
\text { whole }\end{array}$ \\
\hline 1 & 0.587 & 10 & 0.363 & 19 & 0.799 \\
\hline 2 & 0.636 & 11 & 0.536 & 20 & 0.871 \\
\hline 3 & 0.890 & 12 & 0.448 & 21 & 0.536 \\
\hline 4 & 0.871 & 13 & 0.513 & 22 & 0.448 \\
\hline 5 & 0.385 & 14 & 0.587 & 23 & 0.513 \\
\hline 6 & 0.457 & 15 & 0.571 & 24 & 0.587 \\
\hline 7 & 0.592 & 16 & 0.463 & 25 & 0.636 \\
\hline 8 & 0.595 & 17 & 0.623 & 26 & 0.890 \\
\hline 9 & 0.398 & 18 & 0.807 & 27 & 0.871 \\
\hline
\end{tabular}

Table (2) shows that all correlation coefficients between each item and the test as a whole ranged between (0.890-0.363), and this indicated that there was a correlation coefficients between each item and the test as a whole, where they are significant and accepted for the goals of the study application.

\section{The tool reliability}

The tool reliability means that it almost gives the same results if it is applied more than once in similar conditions (Al-Assaf, 1416 H. p 143).

To ensure the reliability of the tool, the reliability coefficient Cronbach Alpha was verified on a survey study consisted of 25 male and females supervisors using (SPPS.25) where its value was (0.882), which is a value that its degree was high and indicated reliability of items of the questionnaire and can be depended on.

\section{The study scale}

Likert Scale was used to identify range of educational supervisors agreement on difficulties of scientific research facing them in the directorates of education in Irbid Governorate.

$\begin{array}{llcc}\text { Importance } & \text { Description } & \text { Range } & \text { Evaluation } \\ 1 & \text { Strongly Disagree } & 1-1-8 & \text { Acceptable } \\ 2 & \text { Disagree } & 1-8-2-6 & \text { Medium } \\ 3 & \text { Neutral } & 2060304 & \text { Good } \\ 4 & \text { Agree } & 3-4-4-2 & \text { Very Good } \\ 5 & \text { Strongly Agree } & 4-2-5 & \text { Excellent }\end{array}$

When correcting Liker Scale to evaluate arithmetic means, we interpret them as follows:

$\begin{array}{ll}\text { High } & >3.5 \\ \text { Medium } & 2.5-3.49 \\ \text { Low } & <2.49\end{array}$
independent: 
1. Independent variables, which included the following:

-Sex: It has two categories (male, female).

- Number of years of experience in educational supervision: It has three levels (less than 5 years, from 5 - less than 10 years, more than 10 years). -Qualification: Ph.D., MA, High diploma.

2. Dependence variables: They included the difficulties of scientific research facing the educational supervisors in the Directorates of education in Irbid Governorate from their point of view as a whole: they were represented by arithmetic means of study sample individuals estimates on items of the tool of scientific research difficulties facing educational supervisors in the Directorates of education in Irbid Governorate from their point of view.

\section{The study procedures}

The tool of the study was built, and its validity and reliability were verified. The questionnaire was distributed to all of the study population in directorate of Irbid with a number of (251), where (25) were for the survey sample. When the researchers viewed the questionnaires, they noticed that (226) wee statistically analyzed. The responses were put in the computer, and the statistical analysis was conducted using (SPSS.25).

\section{Statistical Processing}

To answer the study questions, the descriptive and analytical statistical methods were used by using the statistical package (SPSS.25), which were as follows: descriptive statistic measures to describe the characteristics of the study population in percentages, arithmetic means, standard deviation, and answering the study questions and arranging dimensions in ascending order of materiality. Inferential statistics was also used to make an analysis of male and female supervisors to know if there were significant statistical differences due to sex, scientific qualification and experience in educational supervision among educational supervisors, where the independent t-test and One Way ANOVA were used to find these differences.

\section{The study results}

This part contains the result of study of difficulties of scientific researches facing educational supervisors in the Directorates of education in Irbid Governorate from their point of view through analyzing the study questions, where the arithmetic mean of difficulties was high with a value (4.49) and standard deviation of (0.21).

To know the answer and details of this question, arithmetic mean and standard deviation were counted for every item of the study as shown in table (3).

Table (3) shows the arithmetic means, standard deviations, order according to arithmetic mean for every item of the study in addition to the arithmetic mean, standard deviation of the study itself.

Table (3) arithmetic means and standard deviations for every item of the study $(\mathrm{N}=226)$

\begin{tabular}{|c|l|c|c|c|c|}
\hline Number & \multicolumn{1}{|c|}{ Content of items } & $\begin{array}{c}\text { Arithmetic } \\
\text { mean }\end{array}$ & $\begin{array}{c}\text { Standard } \\
\text { Deviation }\end{array}$ & $\begin{array}{c}\text { Order } \\
\text { based } \\
\text { on } \\
\text { mean }\end{array}$ & $\begin{array}{c}\text { Level } \\
\text { based on } \\
\text { average }\end{array}$ \\
\hline 1 & $\begin{array}{l}\text { Lack of number of scientific journals } \\
\text { that concern with publishing of scientific } \\
\text { researches. }\end{array}$ & 4.83 & 0.48 & 27 & High \\
\hline 2 & $\begin{array}{l}\text { There is no enough background of the } \\
\text { subject that I'm going to research. }\end{array}$ & 4.05 & 0.28 & 3 & High \\
\hline 3 & $\begin{array}{l}\text { Inability to define the importance of the } \\
\text { study. }\end{array}$ & 4.21 & 0.84 & 4 & High \\
\hline
\end{tabular}




\begin{tabular}{|c|c|c|c|c|c|}
\hline 4 & $\begin{array}{l}\text { Inability to define the problem I'm going } \\
\text { to research. }\end{array}$ & 4.39 & 0.71 & 7 & High \\
\hline 5 & $\begin{array}{l}\text { Inability to form the problem of the } \\
\text { study. }\end{array}$ & 4.57 & 0.69 & 11 & High \\
\hline 6 & $\begin{array}{l}\text { Inability to collect information about the } \\
\text { problem, }\end{array}$ & 4.69 & 0.46 & 14 & High \\
\hline 7 & $\begin{array}{l}\text { Inability to set alternatives to the } \\
\text { problem solution. }\end{array}$ & 4.70 & 0.46 & 15 & High \\
\hline 8 & Inability to conclude the results. & 4.40 & 0.49 & 8 & High \\
\hline 9 & $\begin{array}{l}\text { Inability to select the study methodology } \\
\text { I'm going to do. }\end{array}$ & 4.22 & 0.41 & 5 & High \\
\hline 10 & $\begin{array}{l}\text { I am not concerned with scientific } \\
\text { research. }\end{array}$ & 4.71 & 0.45 & 17 & High \\
\hline 11 & Inability to form the literature review. & 4.78 & 0.58 & 21 & High \\
\hline 12 & Lack of related studies. & 4.82 & 0.38 & 26 & High \\
\hline 13 & $\begin{array}{l}\text { Inability to comment on the related } \\
\text { studies. }\end{array}$ & 4.53 & 0.55 & 9 & High \\
\hline 14 & $\begin{array}{l}\text { Difficulty of defining procedural } \\
\text { definitions. }\end{array}$ & 4.78 & 0.50 & 22 & High \\
\hline 15 & Difficulty of forming the limits of study. & 4.61 & 0.52 & 12 & High \\
\hline 16 & $\begin{array}{l}\text { Inability to define the correcting method } \\
\text { of tests on the tool of study. }\end{array}$ & 4.78 & 0.42 & 23 & High \\
\hline 17 & Inability to define the study population & 4.64 & 0.48 & 13 & High \\
\hline 18 & Inability to define the study sample. & 4.76 & 0.43 & 20 & High \\
\hline 19 & $\begin{array}{l}\text { I don't have the ability to determine the } \\
\text { study tools. }\end{array}$ & 4.79 & 0.41 & 24 & High \\
\hline 20 & $\begin{array}{l}\text { I don't have the ability to determine the } \\
\text { study procedures }\end{array}$ & 4.81 & 0.39 & 25 & High \\
\hline 21 & Inability to conclude the study results. & 2.88 & 0.97 & 1 & High \\
\hline 22 & Inability to discuss the study results. & 3.31 & 1.00 & 2 & Medium \\
\hline 23 & $\begin{array}{l}\text { Inability to form the study } \\
\text { recommendations. }\end{array}$ & 4.73 & 0.45 & 18 & High \\
\hline 24 & $\begin{array}{l}\text { Lack of books and modern scientific } \\
\text { studies and references. }\end{array}$ & 4.71 & 0.46 & 16 & High \\
\hline 25 & $\begin{array}{l}\text { Lack of material motives to conduct } \\
\text { scientific researches. }\end{array}$ & 4.74 & 0.44 & 19 & High \\
\hline 26 & $\begin{array}{l}\text { Lack of care offered by Ministry of } \\
\text { Education to scientific research. }\end{array}$ & 4.56 & 0.50 & 10 & High \\
\hline 27 & $\begin{array}{l}\text { Inability of selecting a new subject for } \\
\text { the study. }\end{array}$ & 4.29 & 0.46 & 6 & High \\
\hline \multicolumn{2}{|r|}{ Public Average of study } & 4.49 & 0.21 & & \\
\hline
\end{tabular}

From table (3), we find that the value of the arithmetic mean of difficulties of scientific research facing educational supervisors in the
Directorates of education in Irbid Governorate reached (4.49), and it is considered a high value referring to the scale used in the study. 
It is shown from the table that the first difficulty which stated on "Lack of number of scientific journals that concern with publishing of scientific researches" that got the rank (27) in ascending order based on the means values which was (4.83),then the twelfth difficulty "Lack of related studies" in ascending order based on the means values which was (4.82), the twentieth difficulty which stated on "I don't have the ability to determine the study procedures" with a mean of (4.81), the nineteenth difficulty which stated on "I don't have the ability to determine the study tools" which was the twenty-fourth difficulty in ascending order with a mean of (4.79).

As for difficulties with numbers of (16) which stated on "Inability to define the correcting method of tests on the tool of study", (14) which stated on "Difficulty of defining procedural definitions" and the difficulty No. (11) which stated on "Inability to form the literature review" in the ranks 21, 22, 23 respectively in ascending order with a mean of (4.78).

Whereas the difficulty (21) which stated on "Inability to conclude the study results" was in the first rank in ascending order with a mean of (2.88), followed by the difficulty No. (22) which stated on "Inability to discuss the results" with a mean of (3.31), while the difficulty No. (2) which stated on "There is no enough background of the subject that I'm going to research" was in the third rank with a mean of (4.05) in ascending order, in the fourth rank was the difficulty No. (3) which stated on" Inability to define the importance of the study" with a mean of (4.21), the ninth difficulty which stated on "Inability to select the study methodology I'm going to do" was in the fifth rank with a mean of (4.22), the sixth rank came the difficulty No. (27) which stated on "Inability of selecting a new subject for the study" with a mean of (4.29) and the difficulty (4) which stated on "Inability to define the problem I'm going to research" was in the seventh rank with a mean of $(4,39)$. The study results agreed with the results of study of (AlDhaw, 2018); Al-Rifai and Jibran, 2018) that the difficulties of scientific research were with a high degree, and the results of the study disagree with results of the study of (Mahmoud, 2018; AlHamshari,2017) that degrees of scientific research skills were with medium degree.

Results of inferential analysis of sex, scientific qualification and experience on supervision of the study of the difficulties of scientific research facing educational supervisors in the directorates of education in Irbid Governorate from their point of view

This section contains the answer of the question: Are there statistically significant differences at the level $(\alpha=0.05)$ between the arithmetic averages of the members' estimates of the study community of the difficulties of scientific research facing educational supervisors in the directorates of education in Irbid governorate from their point of view due to variables of (gender, scientific qualification, experience on supervision), where inferential analysis and an independent t-test One Way ANOVA were used to find out these differences and the causes them as shown in the following tables:

In the following table, arithmetic means and standard deviations of difficulties of the scientific research facing educational supervisors in the directorates of education in Irbid Governorate from their point of view due to variables of (gender, scientific qualification and experience on supervision) were found.

Table (4) arithmetic means and standard deviations of difficulties of the scientific research facing educational supervisors in the directorates of education in Irbid Governorate from their point of view due to variables of (gender, scientific qualification, experience on supervision)

\begin{tabular}{|c|c|c|}
\hline Main features & Arithmetic mean & Standard deviation \\
\hline Sex & \\
\hline
\end{tabular}




\begin{tabular}{|c|c|c|}
\hline Male & 4.47 & $\mathbf{0 . 2 1}$ \\
\hline Female & 4.56 & $\mathbf{0 . 2 1}$ \\
\hline \multicolumn{2}{|l|}{ Scientific qualification } \\
\hline PhD & 4.58 & 0.02 \\
\hline MA & 4.41 & 0.01 \\
\hline Diploma & 4.77 & 0.01 \\
\hline \multicolumn{2}{|l|}{ Experience on supervision } \\
\hline Less than 5 years & 4.61 & 0.02 \\
\hline From5-10 years & 4.53 & 0.01 \\
\hline $\begin{array}{c}\text { More than 10 } \\
\text { years }\end{array}$ & 4.30 & 0.02 \\
\hline
\end{tabular}

Table (4) shows that the arithmetic mean of males was $(4,47)$ and the standard deviation was $(0.21)$ which was bigger than the arithmetic of females (4.56) and standard deviation (0.21).

The table also shows that the arithmetic of supervisors who hold the Ph.D. was (4.58) and standard deviation was (0.02), the arithmetic mean of who hold the MA was (4.41) and standard deviation was (0.01) and the arithmetic mean of who hold the high diploma was (4.77) and standard deviation was (0.01).

The two researchers refer this result to that since those who hold high diploma didn't receive the scientific research skills through courses in the university as those hold the MA and Ph.D. The two researchers also refer this study to that those who hold high diploma didn't benefit from the rank system like (expert rank) in the ministry of Education; where among the terms of educational expert rank is you need to write researches and maximum holding an MA. The results of this study disagree with the results of the study of (Mahmoud, 2018), which showed an effect to the Ph.D. qualification.

The arithmetic mean of supervisors whose experience in supervision is 5 years and less was (4.60) and standard deviation was (0.02), whereas the arithmetic mean of whose experience ranged between 5 to 10 tears was (4.53) and standard deviation was (0.01) and the arithmetic mean of whose experience was more 10 years was (4.30) and standard deviation was (0.01).

To know the statistical significant, we did the independent t-test at the level of sex to male and female supervisors and One Way ANOVA at the level of scientific qualification and experience in supervision at (0.05) as shown in table (5).

Table (5) : Independent t-test to know difficulties of the scientific research facing educational supervisors in the directorates of education in Irbid Governorate from their point of view based on $\operatorname{sex}(\mathrm{N}=226)$

\begin{tabular}{|c|c|c|c|}
\hline Item & Value of t-test & Degrees of freedom & Significant level \\
\hline Sex & -2.776 & 224 & $\mathbf{0 . 0 0 6}$ \\
\hline
\end{tabular}

Table (5) shows that there were statistically differences among means of the study individuals response about difficulties of scientific research facing educational supervisors in the directorates of education in Irbid Governorate, where the significant level was (0.006) which is less than (0.05), and these differences due to female supervisors where their arithmetic mean is bigger 
than the males. This result can be interpreted as male are distinguished by loving work in teaching and careful about it more than females since it's the main resource of the family income, and they feel that work, mastery, excellence and advancement in it achieve himself; so they are more careful dedication to work which stimulate them to follow up everything new, seek to master it and do it perfectly.

That is also due to that males turn to learn, develop their skills and knowledge, and attend training sessions that improve and help improve their knowledge, in addition to the learning process among males is considered more safety and stability from the females.

Males may think that the rank system and obtaining a rank through writing scientific researches contributes in meet their ambitions on the economic aspect, because they always think of methods to increase their income and scientific abilities, and this affects their well possession of cognitive efficiencies. These result agree with the results of the results of (Mahmoud, 2018) which concluded that there were significant differences due to the variable of sex for the females, and they disagree with the results of (Al-Dhaw, 2018; AlHamshri, 2017) where they indicated that there were no statistically significant differences of the effect of sex.

Whereas the statistical significant of male and female supervisors concerning scientific qualification and experience in supervision, we did One Way ANOVA test at the level $(0, .05)$ where they were shown in table (6).

Table (6): One Way ANOVA to know difficulties of scientific research facing educational supervisors in the directorates of education in Irbid Governorate from their point of view related to scientific qualification $(\mathrm{N}=\mathbf{2 2 6})$

\begin{tabular}{|c|c|c|c|c|c|}
\hline Item & $\begin{array}{r}\text { Sum of } \\
\text { squares }\end{array}$ & $\begin{array}{r}\text { Degrees of } \\
\text { freedom }\end{array}$ & $\begin{array}{r}\text { Groups } \\
\text { average }\end{array}$ & F Value & Significant level \\
\hline $\begin{array}{c}\text { Among } \\
\text { groups }\end{array}$ & 2.875 & 2 & 1.438 & 45.396 & $\mathbf{. 0 0 0}$ \\
\hline $\begin{array}{c}\text { Inside } \\
\text { groups }\end{array}$ & 7.062 & 223 & .032 & & \\
\hline Total & 9.938 & 225 & & & \\
\hline
\end{tabular}

It is clear from table (6) that there were statistically significant differences where $F$ value $=45.396$ with a statistical significant 0.000 which is less than the significant level 0.05 . These differences refer to supervisors whose qualification is high diploma with arithmetic of 4.777 .

Table (7): One Way ANOVA to know difficulties of scientific research facing educational supervisors in the directorates of education in Irbid Governorate from their point of view related to experience in supervision $(\mathrm{N}=\mathbf{2 2 6})$

\begin{tabular}{|c|c|c|c|c|c|}
\hline Item & $\begin{array}{r}\text { Sum of } \\
\text { squares }\end{array}$ & $\begin{array}{r}\text { Degrees of } \\
\text { freedom }\end{array}$ & $\begin{array}{r}\text { Groups } \\
\text { average }\end{array}$ & F Value & Significant level \\
\hline $\begin{array}{c}\text { Among } \\
\text { groups }\end{array}$ & 3.357 & 2 & 1.679 & 56.878 & $\mathbf{. 0 0 0}$ \\
\hline $\begin{array}{c}\text { Inside } \\
\text { groups }\end{array}$ & 6.581 & 223 & .030 & & \\
\hline Total & 9.938 & 226 & & & \\
\hline
\end{tabular}

It is clear from table (7) that there were statistically significant differences where $\mathrm{F}$ value $=56.878$ with a statistical significant 0.000 which is less than the significant level 0.05 . These differences refer to 
supervisors whose experience in supervision is less than 5 years with a mean of (4.60). The two researchers refer due that to the teaching experience provide teachers with essential information to develop their performance by modern teaching methods and strategies and form efficiencies not existed before where they were provided with and trained during their work and under the school supervision and supervisor.

The reason may also due to the psychological and functional stability of teachers, which motivates them to reach their maximum abilities, and in the light of this, the two researchers see think that teachers with long experience have reached job stability, which motivates the teacher to develop himself professionally through concentration on training sessions which increase their professional improvement featured with their possession of planning, classroom management and evaluation. The reason may also due to educational experience and exchange experiences among mates which may increase the possession of efficiencies and developing them which leads to master methods and strategies inside classroom. The results of this study disagree with the results of the study of (Rimawi and Kurdi, 2015) which showed that there were no differences due to years of experience.

\section{Recommendations}

In the light of the study results, the two researchers recommended the followings:

- Increase the obligatory courses of students of high studies that deal with the foundation of the scientific research and methods of writing scientific studies,

- Work to hold a training sessions which help the educational supervisor to write scientific researches.

-Work on designing leaflets that work to explain how to write scientific researches.

\section{References}

[1] Abboud, Abdul Muhaimin Khalis. (2018). The degree to which Islamic education teachers possess scientific research skills in
Jordan. Unpublished MA thesis, Al al-Bayt University, Mafraq, Jordan.

[2] Abu Rahma, Mohammad Hassan. (2012). Work pressures and their relationship to job satisfaction among educational supervisors in Gaza Governorate. Unpublished MA Thesis, Islamic University, Gaza, Palestine.

[3] Al-Dhaw, Mohammad Ali. (2018). The quality level of scientific research for students of higher education at the Sudanese Bakht Al-Rada University: from the point of view of its faculty members. The Arab Journal for Assurance of University Education. 11 (34), 161-178.

[4] Al-Gharam, jihad. (2015). Problems of scientific research in the Arab world. Journal of Research and Scientific Studies, 9 (1), 229-246.

[5] Al-Hamshari, Omar Ahmed. (2017). Difficulties of scientific research for students of higher education at Zarqa University from their point of view. Zarqa Journal for Humanitarian researches and Studies, 17 (3), 761-776.

[6] Al-Rifai, Samira and Gibran, Ali. (2015). Scientific research problems in Jordanian public universities from the point of view of the faculty members. The Educational Journal, 29 (114), 301-354.

[7] Al-Tartouri, Hussain Mutawa. (2010) Scientific research: its plan, originality, and results. Journal of Al-Quds Open University for Research and Studies, June, (20), 81-115.

[8] Al-Zoubi, Talal. (2018). Difficulties facing students of high education in Jordanian universities in writing master's and doctoral theses from the point of view of supervisors and members of discussion committees. $\mathrm{Al}$ Najah University Journal for Researchand Human Sciences. 32 (9), 1803-1828.

[9] Eideh, Mohammad Suleiman (2007). The Future Perspective of Educational Supervision in Jordan, Al-Farouq Publishing House, Amman. 
[10] Farid, Abradasha. (2018). Scientific research between theory and reality: concepts, relationships and goals. Perspectives for Economic Studies, 3 (1), 90-103.

[11] Hordo Center. (2015). Scientific research in Egypt is whole scholars . and an absent vision. Hordo Center for Support of Digital Expression, Cairo.

[12] Maden, Sharifa. (2012). The reality of scientific research in the Arab world in light of the global knowledge gap. Journal of the Humanities, December (38), 65-85.

[13] Mrain, Youssef and Tawahria, Mona. (2018). Scientific research in light of digital technology, the attractiveness of the mean and the problematic of the content, (reading in the content of Resolution 933 related to scientific plagiarism). Law Journal, 6 (9), 393-408.

[14] Marazka, Jamal. (2013). Improving the quality of scientific research in the field of higher education in the Arab world (reality and solutions). The Third Arab International Conference on Quality Assurance of Higher Education, April 2-4, Jordan, 311-324.

[15] Masoudan, Nesma. (2018). Obstacles of scientific research at the Algerian University. Algerian Journal of Research and Studies, October (4), 6-25.

[16] Ministry of Education (2011). Educational Support, Educational Training Center, Amman, Jordan.

[17] Musaed, Mahmoud (2000). Practical Education between Theory and Practice. Cairo: Dar Al Fikr.

[18] Reis, Jorge J. (2007). Teatchers conceptions of teacher- reaserch and selfperceptions as enquiring : Alongitudinal case study. Teaching and teacher Education، 23 (4)، 402-417.

[19] Rimawi, Omar and Kurdi, Fouad. (2015). Obstacles to scientific research from the point of view of faculty members in the Humanitarian Faculties of Al-Quds
University. Journal of the faculty of Basic Education for Educational and Human Sciences. June (21), 24-36.

[20] Shdaifat, Basil Hamdan. (2014). The role of educational supervisors in developing the professional performance of social studies teachers in the Directorate of education of the Northwestern Badia District in Mafraq Governorate. Damascus University Journal, 30 (2), 299-339.

[21] Shdaifat, Yahya and Qadri, Suleiman. (2005). The effect of using developmental educational supervision in improving the teaching practices of science teachers in Mafraq governorate. Umm Al-Qura University Journal of Educational, Social and Human Sciences, 17 (1), 127-170.

[22] Taylor, A. (2007). Pre-service teachers' view of research; A U.K. case study. Paper presented at the Annual Seminar of the International Society for Teacher Education, Stirling, Scotland.

[23] United Nations Humanitarian Program. (2003). The Arab Fund for Social Economic growth, Arab Human Development Report, United Nations, New York.

[24] Yaghmour, Kholoud and Obaidat, Louai and Hamadneh, Qassim. (2106). The degree of satisfaction of the first three grades' teacher about the supportive educational supervision in light of the variables of sex and experience. Journal of faculty of Education in Educational Sciences, 40 (2) B, 223-271. 